\title{
Clinical significance of laryngopharyngeal reflux in patients with chronic obstructive pulmonary disease
}

\section{Young Ho Jung 1 ,* \\ Doh Young Lee ${ }^{2, *}$ \\ Dong Wook Kim' \\ Sung Soo Park ${ }^{3}$ \\ Eun Young $\mathrm{Heo}^{3}$ \\ Hee Soon Chung ${ }^{3}$ \\ Deog Kyeom Kim ${ }^{3}$}

'Department of OtorhinolaryngologyHead and Neck Surgery, Seoul

Metropolitan Government-Seoul National University Boramae Medical Center, Seoul National University College of Medicine, ${ }^{2}$ Department of Otorhinolaryngology-Head and Neck Surgery, Anam Hospital, Korea University Medical Center, ${ }^{3}$ Division of Pulmonary and Critical Care Medicine, Department of Internal Medicine, Seoul Metropolitan Government-Seoul National University Boramae Medical Center, Seoul National University College of Medicine, Seoul, Republic of Korea

*These authors contributed equally to this work

\author{
This article was published in the following Dove Press journal: \\ International Journal of COPD \\ 15 July 2015 \\ Number of times this article has been viewed
}

Background: Although chronic obstructive pulmonary disease (COPD) is closely associated with gastroesophageal reflux disease (GERD), the clinical significance of laryngopharyngeal reflux (LPR) is not fully understood in COPD.

Methods: Prospective cohorts were established among 118 patients with COPD from March 2013 to July 2014. Thirty-two age-matched and sex-matched normal controls, who had routine health check-ups during the study period, were included. Laryngopharyngeal reflux finding scores (RFS) and reflux symptom index (RSI) for LPR were subjected to association analysis with severity and acute exacerbation of COPD during the 1-year follow-up.

Results: The mean age of patients enrolled in the study was $69.2 \pm 8.8$ years, with $93.2 \%$ being male. Positive RFS ( $>7)$ and RSI $(>13)$ were observed in $51(42.5 \%)$ and six patients $(5.0 \%)$, respectively. RFS and RSI were significantly higher in patients with COPD than in normal, healthy patients $(P<0.001)$. RFS was significantly correlated with residual volume/total lung capacity $(\%, P=0.048)$. Scores for diffuse laryngeal edema, erythema, and hyperemia were significantly higher in the high-risk group (Global Initiative for Chronic Obstructive Lung Disease classification $\mathrm{C}$ and $\mathrm{D} ; P=0.025$ and $P=0.049$, respectively), while RSI was significantly higher in the more symptomatic group (Global Initiative for Chronic Obstructive Lung Disease classification B and D; $P=0.047)$. RSI and RFS were significant predictors for severe acute exacerbation of COPD ( $P=0.03$ and $P=0.047$, respectively), while only RSI was associated with severity of dyspnea.

Conclusion: Laryngeal examination and evaluation of laryngeal reflux symptom could be a surrogate clinical indicator related to severe acute exacerbation of COPD. Further studies of LPR in COPD patients should be considered.

Keywords: COPD, acute exacerbation, laryngopharyngeal reflux, reflux symptom index, reflux finding score

\section{Introduction}

Chronic obstructive pulmonary disease (COPD) is characterized by progressive and irreversible expiratory flow limitation and dyspnea. In patients with COPD, frequent exacerbations are the most prominent and distressing symptom. ${ }^{1}$ Patients with COPD may be particularly vulnerable to reflux and gastroesophageal reflux disease (GERD), which is common in advanced COPD. Although little is known about the prevalence and role of GERD in COPD, exaggerated intrathoracic pressure shifts, increased frequency of coughing, diaphragmatic flattening, and use of $\beta 2$-agonists are thought to exacerbate reflux. ${ }^{2,3}$ However, patients with respiratory disease are often asymptomatic for reflux, and show isolated abnormal proximal reflux, resulting in symptoms that
Correspondence: Deog Kyeom Kim Division of Pulmonary and Critical Care Medicine, Department of Internal Medicine, Seoul Metropolitan Government-Seoul National University Boramae Medical Center, Seoul National University College of Medicine, 20 Boramaero-5-Gil, Dongjak-Gu, Seoul, I56-707, Republic of Korea

Tel +8228702228

Fax +82 283। 2826

Email kimdkmd@snu.ac.kr 
lack sufficient sensitivity and specificity to reliably diagnose or exclude GERD.,5

Laryngopharyngeal reflux (LPR) is considered a different disease from classic reflux or GERD. It is believed that the primary defect in LPR might be upper esophageal sphincter dysfunction in less than half of LPR patients with GERD. ${ }^{6}$ Most patients with LPR have throat symptoms like dysphonia, chronic cough, globus pharyngeus, and chronic throat clearing. ${ }^{7}$ A diagnosis of LPR may be established by interviewing patients and questioning about specific symptoms, videolaryngoscopic evaluation of the larynx, or double probe $\mathrm{pH}$ monitoring. ${ }^{8-10}$ Ambulatory 24-hour double probe (pharyngeal and esophageal) $\mathrm{pH}$ monitoring is highly sensitive and specific for the diagnosis of LPR. ${ }^{11}$ While $\mathrm{pH}$ monitoring is not widely available in clinical practice due to its inconvenience and cost, videolaryngoscopic examination is more easily accessible. Therefore, if a clinical diagnosis of LPR in patients with COPD is identified, physicians may have a valuable tool in the management of reflux-related disease in COPD.

Considering the fact that COPD may exacerbate gastroesophageal reflux, LPR can be aggravated by similar mechanisms. However, limited studies have investigated the association between LPR and COPD or the clinical significance of LPR in patients with COPD. In addition, previous studies have focused on the effect of LPR treatment on COPD, and shown that treatment of LPR resulted in significant improvement in symptoms of COPD. ${ }^{12}$ In contrast, a study of LPR and asthma showed that reflux symptom score and LPR disease index are not reliable for diagnosing LPR in patients with asthma. ${ }^{13}$ In this present study, we aimed to assess the prevalence of LPR in COPD patients, stage the LPR severity, and correlate findings/symptoms with indices of COPD.

\section{Materials and methods Study population}

All of the patients enrolled in the study were recruited from March 2013 to July 2014 at routine follow-up visits to the pulmonary clinic, located at an academic hospital in South Korea. The inclusion criteria required participants to be aged 40 years or older, diagnosed with COPD based on guidelines, ${ }^{1}$ have a smoking history of over ten packs/year, and be able to provide written informed consent. Exclusion criteria included previous diagnosis of LPR or GERD, recent history of exposure to proton pump inhibitors within 2 months, airflow limitation resulting from parenchymal destruction with previous infection (eg, pulmonary tuberculosis, diffuse bronchiectasis), a recent history of alcohol abuse, known esophageal disease including cancer, achalasia and peptic ulcer disease, and any clinically significant concurrent disease. COPD patients with exacerbation within 1 month of enrollment were also excluded. The institutional review board (approval 06-2011-72) of Seoul National University Boramae Medical Center approved all of the protocols and study design, and all patients gave written informed consent. Data on demographic, physiologic, and clinical characteristics, including age, sex, height, body weight, smoking status, spirometric data, and use of respiratory medications, were obtained from each patient.

\section{Study protocol}

This cross-sectional study evaluated the prevalence of LPR in COPD patients, and prospectively observed the patients for 1 year after enrollment to measure the frequency of acute exacerbations of COPD (AECOPD). On enrolment, patients were surveyed with the modified Medical Research Council dyspnea scale and laryngeal symptom index (RSI). ${ }^{8,14}$ Spirometric data were also collected. Patients were regularly followed at 2, 6, and 12 months after initial registration. The number of acute moderate or severe exacerbations were evaluated at each follow-up. The severity of AECOPD was determined by the requirement for antibiotics or systemic steroids (moderate) and admission to hospital due to exacerbation (severe).

Laryngoscopy was performed by an otolaryngologist (YHJ) and interpreted by two independent otolaryngologists (YHJ and DYL). Reflux finding scores (RFS) were summated by calculating the score of each of the findings, ie, subglottic edema $(0 / 2)$, vocal fold edema $(0 / 1 / 2 / 3 / 4)$, ventricular obliteration $(0 / 2 / 4)$, diffuse laryngeal edema $(0 / 1 / 2 / 3 / 4)$, erythema/hyperemia $(0 / 2 / 4)$, posterior commissure hypertrophy $(0 / 1 / 2 / 3 / 4)$, thick mucus (0/2), and granuloma (0/2). LPR was defined as an RFS over 7 and an RSI over $13 .^{8,10}$

To compare RFS and RSI of non-COPD controls, 32 agematched and sex-matched normal controls who had routine health check-ups during the study period were included. The controls also did not have a previous history of GERD or LPR, and any pulmonary disease was ruled out by chest $\mathrm{X}$-ray and pulmonary function testing.

\section{Statistical analysis}

Continuous variables were presented as the mean \pm standard deviation, and categorical variables as frequencies and group percentages. Continuous variables were compared according to the severity of airflow limitation (Global Initiative for Chronic Obstructive Lung Disease grade) and acute 
exacerbation of COPD by independent samples $t$-test or analysis of variance test. Categorical variables were compared using chi-square analysis or a Cochran-Armitage trend test. RFS and RSI were considered both continuous and categorical variables (RFS positive $>7$ and negative $\leq 7$, RSI positive $>13$ and negative $\leq 13$ ). The established risk factors for exacerbations were included in a bivariate logistic regression analysis model. The odds ratios and 95\% confidence intervals were then calculated. $P<0.05$ was considered to be statistically significant. The statistical analysis was performed using Statistical Package for the Social Sciences version 20.0 software (SPSS Inc, Chicago, IL, USA).

\section{Results}

\section{Characteristics of study population}

The detailed characteristics of the study population are summarized in Table 1. A total of 118 patients with COPD were enrolled. The mean age was $69.2 \pm 8.8$ years and the male to female ratio was 110:8. The mean follow-up duration was 14.3 \pm 5.4 months. According to the Global Initiative for Chronic Obstructive Lung Disease classification, patients were categorized into four groups: A, low risk with less

Table I Characteristics of COPD patients $(n=\mid 18)$

\begin{tabular}{|c|c|}
\hline Age, years, mean $( \pm S D)$ & $69.2( \pm 8.8)$ \\
\hline $\operatorname{Sex}(M: F)$ & $110: 8$ \\
\hline Follow-up duration (months), mean $( \pm S D)$ & $14.3( \pm 5.4)$ \\
\hline BMI $\left(\mathrm{kg} / \mathrm{m}^{2}\right)$, mean $( \pm \mathrm{SD})$ & $22.1( \pm 3.2)$ \\
\hline Dyspnea (mMRC), mean $( \pm \mathrm{SD})$ & $1.82( \pm 0.70)$ \\
\hline \multicolumn{2}{|l|}{ Spirometry, mean $( \pm S D)$} \\
\hline $\mathrm{FEV}_{1}(\%)$ & $53.1( \pm 18.4)$ \\
\hline FVC (\%) & $85.9( \pm 16.9)$ \\
\hline$\Delta \mathrm{FEV}_{1}, \%$ & $6.4( \pm 9.2)$ \\
\hline RV/TLC (\%) & $49.5( \pm 16.0)$ \\
\hline $\mathrm{DL}_{\mathrm{co}}(\%)$ & $83.9( \pm 23.3)$ \\
\hline \multicolumn{2}{|l|}{ GOLD classification, n (\%) } \\
\hline A (low risk, less symptoms) & $27(22.9 \%)$ \\
\hline B (low risk, more symptoms) & $45(38.1 \%)$ \\
\hline C (high risk, less symptoms) & $13(11.0 \%)$ \\
\hline D (high risk, more symptoms) & $33(28.0 \%)$ \\
\hline \multicolumn{2}{|l|}{ Patients with acute exacerbation, $n$ (\%) } \\
\hline Moderate & $23(19.5 \%)$ \\
\hline Severe & $15(12.7 \%)$ \\
\hline \multicolumn{2}{|l|}{ Number of acute exacerbations*, mean (range) } \\
\hline Moderate & $0.27(0-4)$ \\
\hline Severe & $0.19(0-3)$ \\
\hline
\end{tabular}

Note: *Frequency of acute exacerbation reported by patients and medical chart during the study period.

Abbreviations: BMI, body mass index; COPD, chronic obstructive pulmonary disease; $\mathrm{DL}_{\mathrm{co}}$, carbon monoxide diffusing capacity; $\mathrm{FEV}_{1}$, forced expiratory volume in I second; $\triangle \mathrm{FEV}_{1}$, post bronch-odilator $\mathrm{FEV}$, change; FVC, forced vital capacity; GOLD, Global Initiative for Chronic Obstructive Lung Disease; mMRC, modified Medical Research Council dyspnea scale; RV, residual volume; TLC, total lung capacity. symptoms $(\mathrm{n}=27,22.9 \%) ; \mathrm{B}$, low risk with more symptoms $(\mathrm{n}=45,38.1 \%) ; \mathrm{C}$, high risk with less symptoms $(\mathrm{n}=13$, $11.0 \%)$; and D, high risk with more symptoms $(n=33,28.0 \%)$. The four groups showed no significant difference in age, sex ratio, or body mass index. The follow-up duration was significantly shorter in group A ( $P=0.008$; Table 2$)$. In the entire cohort, moderate and severe AECOPD was observed in 23 (19.5\%) and 15 patients (12.7\%), respectively. Both moderate and severe AECOPD were more frequent in groups $\mathrm{C}$ and $\mathrm{D}$ than in groups $\mathrm{A}$ and $\mathrm{B}(P<0.001$; Table 2$)$. The mean RFS and RSI were $6.86 \pm 2.60$ and $4.57 \pm 4.71$, respectively. Positive RFS $(>7)$ and RSI $(>13)$ were observed in $51(42.5 \%)$, and six $(5.0 \%)$ patients, respectively. Only five patients $(4.2 \%)$ were diagnosed with LPR by RFS and RSI criteria. Comparing the area under receiver operating curve for RSI, 8.5 points of RSI coincided with the cut-off value of RSI ( 7 points) for LPR, which was lower than the usual cut-off value of RSI (13 points) for LPR.

\section{Association between LPR parameters, AECOPD, and dyspnea severity}

When comparing the low-risk groups (A and B) and the high-risk groups (C and D), the total RFS and RSI were not significantly different ( $P=0.344$ and $P=0.252$, respectively), although positive correlations in trends were suggested in each parameter for LPR (Table 3). With regard to the RFS parameter, diffuse laryngeal edema and erythema/hyperemia showed significantly higher scores in the high-risk groups than in the low-risk groups ( $P=0.025$ and $P=0.049$, respectively). Patients with RSI $>3$ were more prevalent in the high-risk groups $(P=0.032)$. When comparing the groups with less symptoms (groups A and C) with the groups with more symptoms (groups B and D), RFS and each of the parameters showed no significant difference (Table 3). However, total RSI was significantly higher in the groups with more symptoms $(P=0.047)$, and there were more patients with RSI $>8.5$ in the groups with more symptoms $(P=0.006)$.

Multivariate analysis revealed that no parameter was significantly associated with acute moderate exacerbation. However, both RSI (continuous or dichotomous) and RFS (continuous) were significantly associated with acute severe exacerbation $(P=0.03, P=0.01$, and $P=0.047$, respectively; Table 3$)$. There was a significant negative correlation between RFS and residual volume/total lung capacity (\%) in simple correlation analysis $(P=0.048)$, while correlation of RFS and RSI with forced expiratory volume in 1 second $\left(\mathrm{FEV}_{1} ; \%\right)$, residual volume/total lung capacity (\%), and diffusing capacity of the lungs 
Table 2 Demographic and spirometric characteristics according to GOLD classification

\begin{tabular}{|c|c|c|c|c|c|}
\hline & $\begin{array}{l}\text { A }(n=27), \\
\text { (low risk, less } \\
\text { symptoms) }\end{array}$ & $\begin{array}{l}\text { B ( } n=45), \\
\text { (low risk, more } \\
\text { symptoms) }\end{array}$ & $\begin{array}{l}C(n=13), \\
\text { (high risk, less } \\
\text { symptoms) }\end{array}$ & $\begin{array}{l}D(n=33), \\
\text { (high risk, more } \\
\text { symptoms) }\end{array}$ & $P$-value \\
\hline Age, mean $( \pm S D)$ & $67.8( \pm 9.5)$ & $69.5( \pm 8.2)$ & $70.8( \pm 9.7)$ & $69.2( \pm 8.8)$ & 0.773 \\
\hline $\operatorname{Sex}(M: F)$ & 26:1 & $40: 5$ & $13: 0$ & $31: 2$ & 0.438 \\
\hline Follow-up duration (months), mean $( \pm S D)$ & $11.5( \pm 6.2)$ & $15.0( \pm 4.9)$ & $13.3( \pm 5.8)$ & $15.9( \pm 4.5)$ & 0.008 \\
\hline BMI $\left(\mathrm{kg} / \mathrm{m}^{2}\right)$, mean $( \pm \mathrm{SD})$ & $23.0( \pm 4.1)$ & $22.1( \pm 2.9)$ & $21.6( \pm 2.9)$ & $21.6( \pm 2.9)$ & 0.389 \\
\hline Dyspnea (mMRC), mean $( \pm \mathrm{SD})$ & $1.00( \pm 0.00)$ & $2.16( \pm 0.37)$ & $1.00( \pm 0.00)$ & $2.36( \pm 0.55)$ & $<0.001$ \\
\hline \multicolumn{6}{|l|}{ Spirometry, mean $( \pm S D)$} \\
\hline $\mathrm{FEV}_{1}(\%)$ & $72.9( \pm 12.2)$ & $69.9( \pm I I .2)$ & $62.7( \pm 19.3)$ & $43.4( \pm 12.9)$ & $<0.001$ \\
\hline FVC (\%) & $91.0( \pm \mid 4.5)$ & $92.1( \pm 18.5)$ & $88.9( \pm \mid 4.3)$ & $76.3( \pm 17.9)$ & 0.001 \\
\hline$\Delta \mathrm{FEV}_{1}, \%$ & $5.2( \pm 6.2)$ & $5.1( \pm 8.6)$ & $7.9( \pm 7.8)$ & $8.4( \pm I 1.8)$ & 0.374 \\
\hline RV/TLC (\%) & $45.5( \pm 12.1)$ & $46.5( \pm 10.8)$ & $40.0( \pm 5.2)$ & $59.2( \pm 22.2)$ & 0.061 \\
\hline $\mathrm{DL}_{\mathrm{co}}(\%)$ & $91.0( \pm 22.9)$ & $85.6( \pm 15.9)$ & $70.8( \pm 28.5)$ & $79.0( \pm 27.8)$ & 0.159 \\
\hline \multicolumn{6}{|l|}{ Patients with acute exacerbation, $\mathrm{n}(\%)$} \\
\hline Moderate & $3(11.1 \%)$ & $3(6.7 \%)$ & $6(46.2 \%)$ & II (33.3\%) & 0.001 \\
\hline Severe & 0 & 0 & $2(15.4 \%)$ & $13(39.4 \%)$ & $<0.001$ \\
\hline \multicolumn{6}{|l|}{ Number of acute exacerbations, mean (range) } \\
\hline Moderate & $0.11(0-I)$ & $0.07(0-1)$ & $0.69(0-2)$ & $0.52(0-4)$ & $<0.001$ \\
\hline Severe & 0 & 0 & $0.31(0-3)$ & $0.58(0-3)$ & $<0.001$ \\
\hline
\end{tabular}

Abbreviations: BMI, body mass index; $\mathrm{DL}_{\mathrm{CO}}$, carbon monoxide diffusing capacity; FEV , forced expiratory volume in I second; $\Delta \mathrm{FEV}$, post bronchodilator $\mathrm{FEV}$, change; FVC, forced vital capacity; GOLD, Global Initiative for Chronic Obstructive Lung Disease; mMRC, modified Medical Research Council dyspnea scale; RV, residual volume; TLC, total lung capacity.

for carbon monoxide (\%) showed no significant correlation (Figure 1). With regard to the severity of dyspnea measured with the modified Medical Research Council scale, RSI was a significant predictor for severe dyspnea after adjusting for age, sex, body mass index, and $\mathrm{FEV}_{1} \%$ predicted (Table 4).

\section{Comparison between COPD patients and normal controls}

Normal controls showed mean RFS and RSI scores of $3.13 \pm 2.83$ and $3.25 \pm 3.57$, respectively. RFS and RSI were significantly higher in patients with COPD $(P<0.001$; Figure 2). RFS findings indicated that, subglottic edema, vocal fold edema, ventricular obliteration, diffuse laryngeal edema, and posterior commissure hypertrophy were significantly prevalent or more severe in patients with COPD than in normal controls (Table 5, Figure 3).

\section{Discussion}

GERD is a well-known comorbidity of COPD, ${ }^{12,15}$ and is negatively associated with symptoms, quality of life, and exacerbation of COPD. ${ }^{16-18}$ However, the association between

Table 3 RFS and RSI according to risk and symptoms

\begin{tabular}{|c|c|c|c|c|c|c|}
\hline GOLD classification & $\begin{array}{l}\text { Low risk } \\
(\mathrm{n}=72)\end{array}$ & $\begin{array}{l}\text { High risk } \\
(n=46)\end{array}$ & $P$-value & $\begin{array}{l}\text { Less symptoms } \\
(n=40)\end{array}$ & $\begin{array}{l}\text { More symptoms } \\
(n=78)\end{array}$ & $P$-value \\
\hline \multicolumn{7}{|l|}{ RFS } \\
\hline RFS $>7$ & 30 (4I.7\%) & $19(41.3 \%)$ & 0.562 & $17(42.5 \%)$ & $32(41.0 \%)$ & 0.516 \\
\hline Total & $6.79( \pm 2.65)$ & $6.96( \pm 2.54)$ & 0.736 & $6.90( \pm 2.78)$ & $6.83( \pm 2.52)$ & 0.899 \\
\hline Subglottic edema & $1.53( \pm 0.86)$ & $1.74( \pm 0.68)$ & 0.160 & $1.55( \pm 0.85)$ & $1.64( \pm 0.77)$ & $0.57 \mid$ \\
\hline Vocal fold edema & $1.00( \pm 0.87)$ & $1.00( \pm 0.89)$ & 0.942 & $0.98( \pm 0.86)$ & $1.01( \pm 0.89)$ & 0.824 \\
\hline Ventricular obliteration & $1.33( \pm 1.01)$ & $1.13( \pm 1.00)$ & 0.287 & $1.35( \pm 1.05)$ & $1.21( \pm 0.99)$ & 0.471 \\
\hline Diffuse laryngeal edema & $\mathrm{I} .44( \pm 0.77)$ & $1.09( \pm 0.87)$ & 0.025 & $1.45( \pm 0.93)$ & $1.23( \pm 0.76)$ & 0.171 \\
\hline Erythema/hyperemia & $0.03( \pm 0.24)$ & $0.22( \pm 0.76)$ & 0.050 & $0.05( \pm 0.32)$ & $0.13( \pm 0.59)$ & 0.350 \\
\hline Posterior commissure hypertrophy & $1.21( \pm 0.65)$ & $1.39( \pm 0.54)$ & 0.099 & $1.18( \pm 0.59)$ & $1.33( \pm 0.62)$ & 0.180 \\
\hline Thick mucus & $0.25( \pm 0.67)$ & $0.39( \pm 0.80)$ & 0.302 & $0.35( \pm 0.77)$ & $0.28( \pm 0.70)$ & $0.64 I$ \\
\hline Granuloma & 0 & 0 & - & 0 & 0 & - \\
\hline \multicolumn{7}{|l|}{ RSI } \\
\hline RSI $>13$ & I (I.4\%) & 5 (10.9\%) & 0.032 & I (2.5\%) & 5 (6.4\%) & 0.340 \\
\hline $\mathrm{RSI}>8.5^{*}$ & $8(11.1 \%)$ & $9(19.6 \%)$ & 0.152 & I $(2.5 \%)$ & $16(20.5 \%)$ & 0.006 \\
\hline Total & $4.07( \pm 3.26)$ & $5.36( \pm 6.33)$ & 0.153 & $3.54( \pm 2.98)$ & $5.09( \pm 5.32)$ & 0.047 \\
\hline
\end{tabular}

Note: *RSI value calculated with receiver operating characteristic curve which is expected to be compatible with RFS 7. Data are presented as mean \pm SD, unless otherwise specified. Abbreviations: GOLD, Global Initiative for Chronic Obstructive Lung Disease; RFS, reflux finding score; RSI, reflux symptom index. 


\section{A}

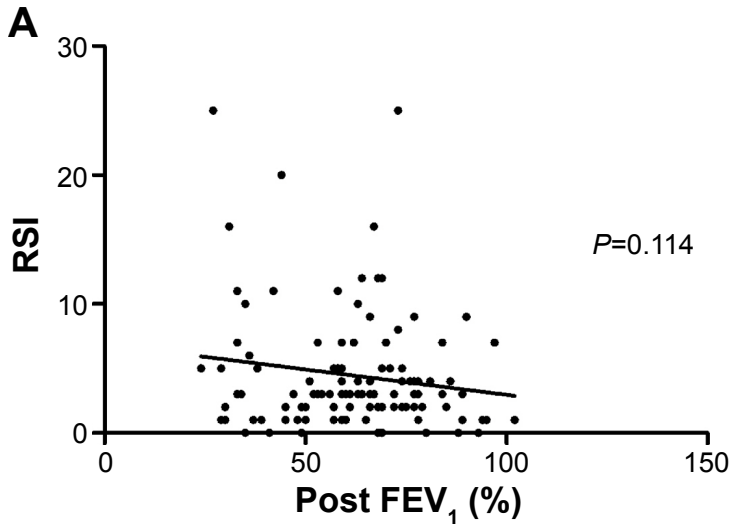

C
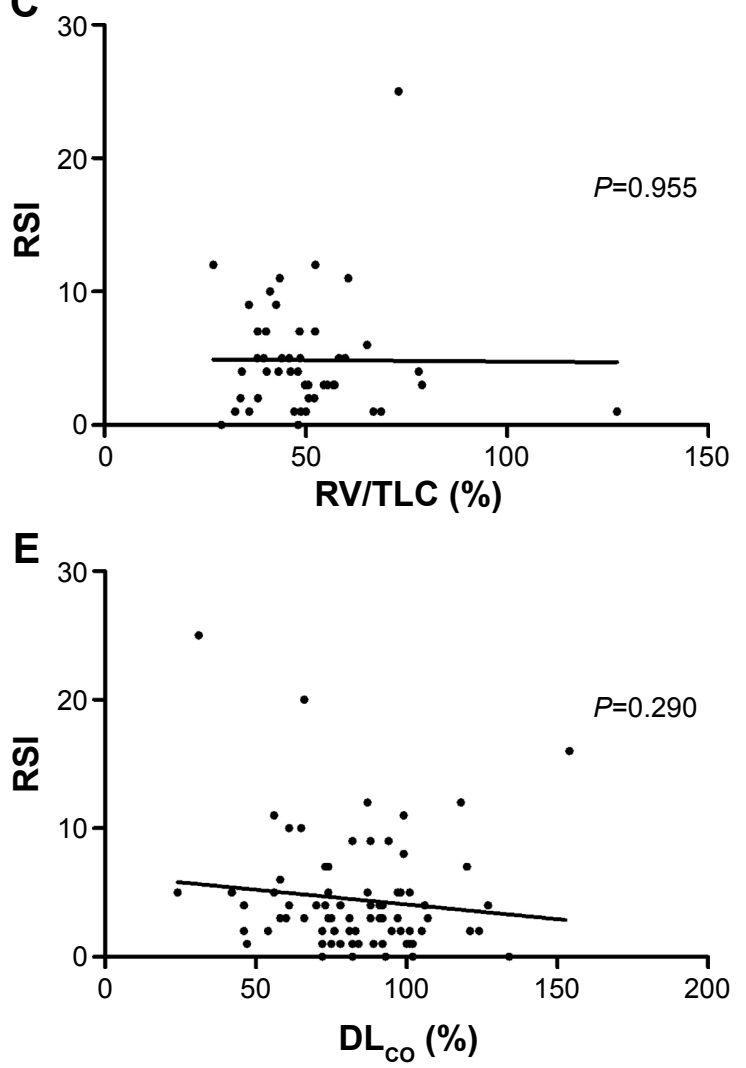

B

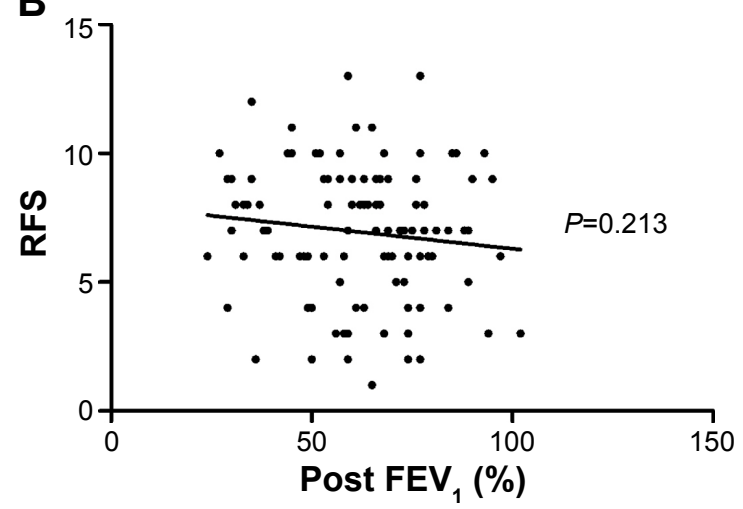

D

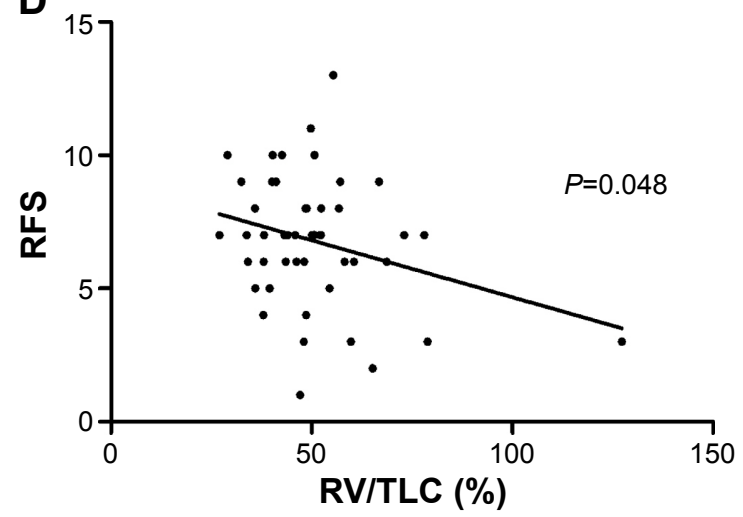

F

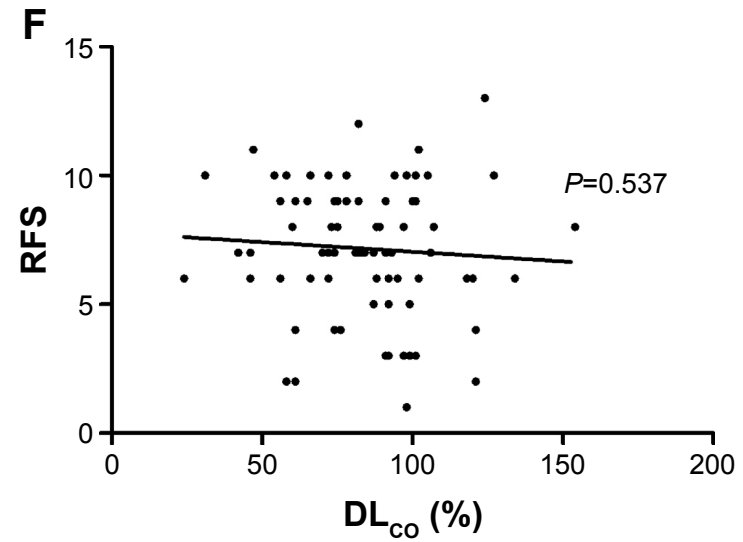

Figure I Correlation of reflux symptom index and finding score with post FEV (\%) (A, B), RV/TLC (\%) (C, D), and DL Abbreviations: COPD, chronic obstructive pulmonary disease; $\mathrm{DL}_{\mathrm{co}}$, carbon monoxide diffusing capacity; $F \mathrm{~V}_{1}$, forced expiratory volume in I second; RFS, reflux finding score; RSI, reflux symptom index; RV, residual volume; TLC, total lung capacity.

COPD and LPR, a laryngeal manifestation and airway effect of GERD, has not been extensively studied. To the best of our knowledge, this is the first report of an association between LPR and AECOPD. In the course of this study, we identified features of LPR in patients with COPD.

The prevalence of GERG reported has been varied in studies, according to differences in study population and diagnostic definition. Self-reported GERD was found in $29 \%$ of patients in the COPDGene study cohort, ${ }^{18}$ and $28 \%$ of COPD patients reported GERD in a nationwide health insurance data survey. ${ }^{15} \mathrm{We}$ excluded patients with alleged gastric disorders, and RFS-based LPR was found in 42.5\% of patients, whereas RSI-defined LPR was identified in only $5.0 \%$ of patients with COPD in this study. Although the prevalence of LPR in COPD has rarely been reported in large populations, RFS-defined LPR was higher than expected considering that LPR may be a part of GERD. Nevertheless, it has been reported that in severe COPD, pathologic reflux, as defined by $\mathrm{pH}$ monitoring, was increased in up to $62 \%$ of subjects. Consistent with our results, $58 \%$ of these patients did not report any reflux symptoms. ${ }^{18,19}$ In other words, symptomdefined prevalence may be lower than objectively-defined 
Table 4 Multivariate analysis for association between indices of reflux and severe acute exacerbation/mMRC*

\begin{tabular}{lccll}
\hline Variables & Odds ratio & $\mathbf{9 5 \%} \mathbf{C l}$ & Beta & P-value \\
\hline Severe acute exacerbation & & & & \\
FEV,$(\%)$ & 0.95 & $0.91-0.98$ & -0.06 & 0.009 \\
RSI & 1.15 & $1.01-1.30$ & 0.14 & 0.031 \\
RSI $(\leq 13$ versus $>13)$ & 0.08 & $0.01-0.58$ & -2.47 & 0.012 \\
RFS & 1.29 & $1.00-1.67$ & 0.26 & 0.047 \\
RFS $(\leq 7$ versus $>7)$ & 2.40 & $0.79-7.35$ & 0.88 & 0.122 \\
mMRC & & & & \\
FEV $(\%)$ & 0.01 & $-0.02-0.01$ & -0.35 & $<0.001$ \\
RSI & 0.03 & $0.003-0.06$ & 0.21 & 0.028 \\
RSI $(\leq 13$ versus $>13)$ & 0.49 & $-0.09-1.08$ & 0.16 & 0.104 \\
RFS & 0.01 & $-0.07-0.01$ & 0.04 & 0.682 \\
RFS $(\leq 7$ versus $>7)$ & 0.01 & $-0.24-0.27$ & 0.01 & 0.098 \\
\hline
\end{tabular}

Notes: *Adjusted with age, sex, and BMI. RSI and RFS were tested in separate models due to their interaction.

Abbreviations: $\mathrm{BMI}$, body mass index; $\mathrm{Cl}$, confidence interval; $\mathrm{FEV}_{1}$, forced expiratory volume in I second; mMRC, modified Medical Research Council dyspnea scale; RFS, reflux finding score; RSI, reflux symptom index.

pathologic findings. The correlation between RFS and RSI was low in our study group, even considering the small number of subjects (Figure S1). There are two hypotheses: First, the common respiratory symptoms of COPD can be presented with those in RSI such as dysphonia, throat clearing, excess throat mucus, and cough. As a result, any symptoms they may be experiencing could be ignored or attributed to more common daily symptoms rather than LPR. Supporting our hypothesis, the number of patients with an RSI $>13$ (the cut-off value for LPR in the general population) was very small in the main analysis and additive analysis when compared with normal controls, although the mean difference in RSI was significantly different (Figure 2A). In contrast, the number of patients with RFS greater than 7 (the cutoff value for LPR in the general population) was more prevalent in COPD patients (Figure 2B). Second, there is a possibility of overdiagnosis of RFS. However, the second explanation may be less likely considering that the prevalence of symptomatic GERD was lower than that measured by ambulatory $\mathrm{pH}$ monitoring, ${ }^{19}$ and a higher prevalence and more severe
Table 5 Comparison of RFS between patients with COPD and normal controls matched for age and sex

\begin{tabular}{|c|c|c|c|}
\hline RFS variables & COPD $(n=32)$ & Normal $(n=32)$ & $P$-value \\
\hline \multicolumn{4}{|c|}{ Subglottic edema* } \\
\hline 0 & $4(12.5 \%)$ & $17(53.1 \%)$ & \multirow[t]{2}{*}{0.001} \\
\hline 2 & $28(87.5 \%)$ & 15 (46.9\%) & \\
\hline \multicolumn{4}{|c|}{ Vocal fold edema* } \\
\hline 0 & $12(37.5 \%)$ & $26(81.3 \%)$ & \multirow[t]{5}{*}{0.003} \\
\hline I & 9 (28.1\%) & $4(12.5 \%)$ & \\
\hline 2 & $9(28.1 \%)$ & I (3.1\%) & \\
\hline 3 & $2(6.3 \%)$ & I (3.1\%) & \\
\hline 4 & 0 & 0 & \\
\hline \multicolumn{4}{|c|}{ Ventricular obliteration* } \\
\hline 0 & $12(37.5 \%)$ & 27 (84.4\%) & \multirow[t]{3}{*}{$<0.00$ I } \\
\hline 2 & $20(62.5 \%)$ & $5(15.6 \%)$ & \\
\hline 4 & 0 & 0 & \\
\hline \multicolumn{4}{|c|}{ Diffuse laryngeal edema* } \\
\hline 0 & $6(18.8 \%)$ & $16(50.0 \%)$ & \multirow[t]{5}{*}{0.008} \\
\hline 1 & $14(43.7 \%)$ & 14 (43.7\%) & \\
\hline 2 & $10(31.2 \%)$ & $2(6.3 \%)$ & \\
\hline 3 & $2(6.3 \%)$ & 0 & \\
\hline 4 & 0 & 0 & \\
\hline \multicolumn{4}{|c|}{ Erythema/hyperemia } \\
\hline 0 & $31(96.9 \%)$ & $30(93.7 \%)$ & \multirow[t]{3}{*}{0.500} \\
\hline 2 & $\mathrm{I}(3.1 \%)$ & $2(6.3 \%)$ & \\
\hline 4 & 0 & 0 & \\
\hline \multicolumn{4}{|c|}{ Posterior commissure hypertrophy* } \\
\hline 0 & $\mathrm{I}(3.1 \%)$ & $12(37.5 \%)$ & \multirow[t]{5}{*}{0.005} \\
\hline I & $18(56.3 \%)$ & 14 (43.8\%) & \\
\hline 2 & $12(37.5 \%)$ & $5(15.6 \%)$ & \\
\hline 3 & $\mathrm{I}(3.1 \%)$ & I (3.1\%) & \\
\hline 4 & 0 & 0 & \\
\hline \multicolumn{4}{|l|}{ Thick mucus } \\
\hline 0 & $28(87.5 \%)$ & $28(87.5 \%)$ & \multirow[t]{2}{*}{0.650} \\
\hline 2 & $4(12.5 \%)$ & $4(12.5 \%)$ & \\
\hline \multicolumn{4}{|l|}{ Granuloma } \\
\hline 0 & 32 (100\%) & $32(100 \%)$ & \multirow[t]{2}{*}{ NA } \\
\hline 2 & 0 & 0 & \\
\hline
\end{tabular}

Note: *Significantly predominant in COPD patients.

Abbreviations: COPD, chronic obstructive pulmonary disease; NA, not applicable; RFS, reflux finding score.

grade of RFS was identified in patients with COPD (Table 5) when compared with age-matched and sex-matched normal subjects. In this respect, LPR findings in COPD could be an indicator of acid reflux rather than reflux symptoms in patients with COPD.
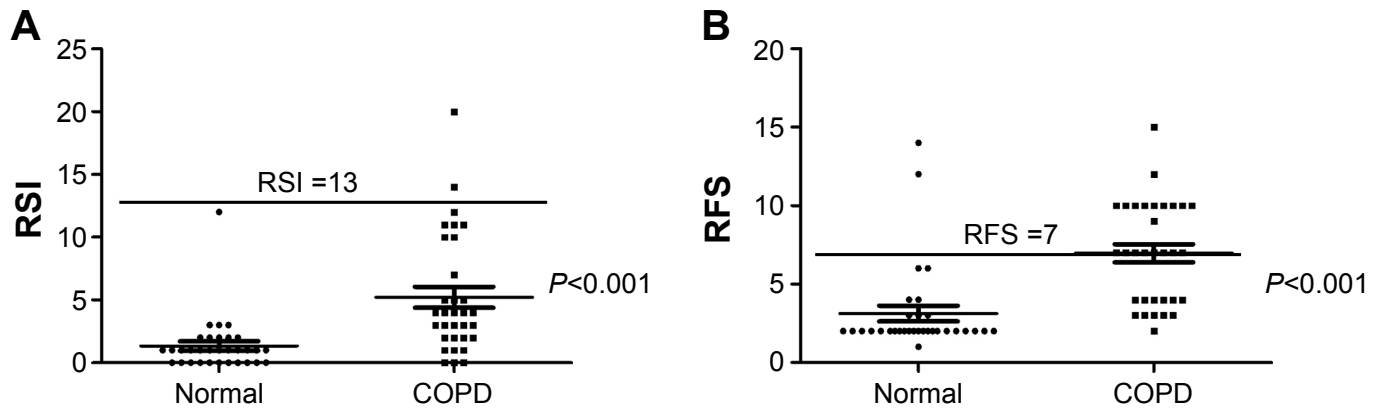

Figure 2 RSI (A) and RFS (B) of patients with COPD and a normal control.

Abbreviations: COPD, chronic obstructive pulmonary disease; RFS, reflux finding score; RSI, reflux symptom index. 


\section{Reflux finding score (COPD versus normal)}

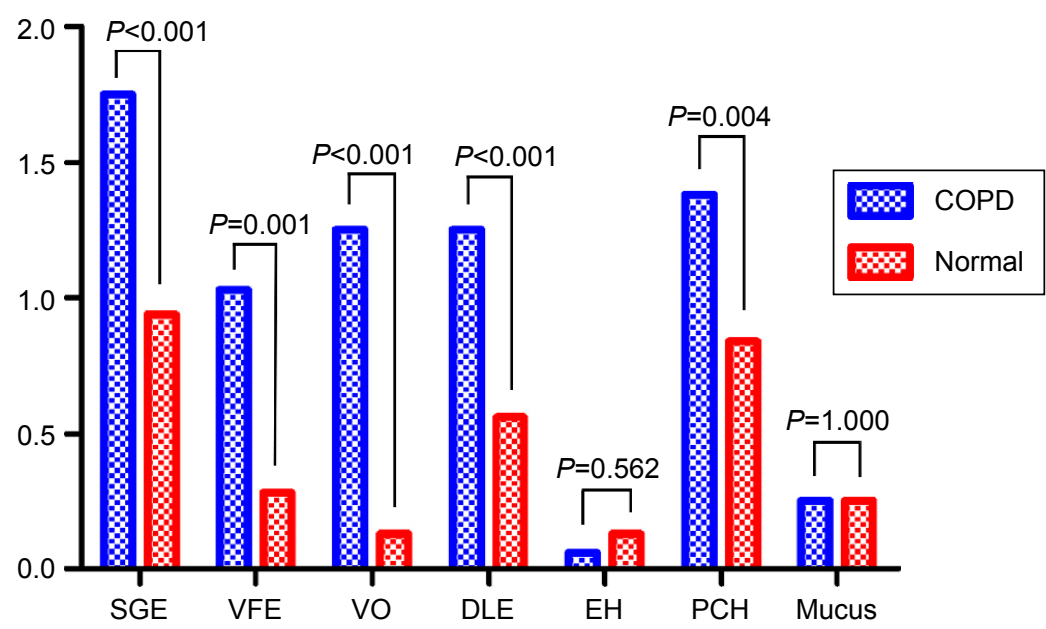

Figure 3 Reflux finding score of patients with COPD and normal controls. Abbreviations: COPD, chronic obstructive pulmonary disease; DLE, diffuse laryngeal edema; EH, erythema/hyperemia; PCH, posterior commissure hypertrophy; SGE, subglottic edema; VFE, vocal fold edema; VO, ventricular obliteration.

We found that RFS and RSI were associated with severe AECOPD independent of age, sex, $\mathrm{FEV}_{1}$, or body mass index. In addition, the prevalence and grade of RFS and severity of RSI increased according to the increasing COPD severity; the failure of this association to reach statistical significance could be attributable to the small number of subjects.

AECOPD is a major treatment target in COPD,${ }^{20}$ and many contributing factors have been reported, including GERD. ${ }^{21,22}$ Our study is the first to examine the possible relationship between LPR and AECOPD. Dysfunction of the upper esophageal sphincter (UES) is considered a critical pathogenic step in LPR, and is also associated with dysfunction of the UES as well as the lower esophageal sphincter, as shown in an esophageal motility study. ${ }^{23}$ The role of the UES is more emphasized during coughing, and is important in preventing esophagopharyngeal reflux during cough, even in elderly people. ${ }^{24}$ Hyperinflation-induced poor exercise capacity, higher intrathoracic pressure, and flattening of the diaphragm are expected to contribute to the pathogenesis of GERD in COPD. ${ }^{2,3}$ If a similar mechanism occurred in patients with LPR, the increased residual volume (145.6\% of predicted value) in our study population can be explained by the proposed mechanism. Moreover, our findings demonstrate that the residual volume/total lung capacity (\%) was significantly correlated with RFS. This supports the previous theory concerning the correlation between LPR and COPD, along with the association of COPD with reflux findings rather than reflux symptoms as mentioned previously. Among the RFS, diffuse laryngeal edema and erythema/hyperemia showed significantly higher scores in the high-risk group. Subglottic edema and posterior commissure hypertrophy were typical and frequent findings in LPR patients without COPD (data not shown). We consider that these findings could be unique for COPD, especially for the high-risk groups.

The present study had some limitations. First, as mentioned earlier, it had weak statistical power due to the small number of patients and had a lack of generalizability due to the preponderance of male subjects. We tried to exclude patients with alleged reflux-related gastrointestinal disease and those who had used proton pump inhibitors. A high prevalence of GERD and prevalent use of proton pump inhibitors led us to restrict the enrolled numbers of study subjects. As a result, statistical power was not achieved for some parameters. Second, a therapeutic trial with proton pump inhibitors and follow-up laryngeal examination were not performed in this study. Thus, the clinical significance of each RFS finding cannot be discussed. Third, RSI and RFS could have limited sensitivity and specificity for diagnosing the LPR. The innate weakness in diagnosing LPR is that there is no diagnostic method of gold standard yet. Although double probe $\mathrm{pH}$ monitoring could be used for suspicious patients, poor cooperation of the patients from discomfort during the test and lack of strong correlation with the LPR symptom limit the wide appliance of the double probe $\mathrm{pH}$ monitoring. In this study, diagnostic definition of LPR was based on RSI and RFS, because those parameters were validated in terms of the correlation and response to treatment. 


\section{Conclusion}

In summary, laryngeal reflux findings were prevalent in patients with COPD, and were found in $42.5 \%$ of subjects in this study. RFS and RSI for LPR indicated significant risk factors for AECOPD. Laryngeal examination may be clinically indicated during AECOPD, and further studies of LPR in COPD patients should be considered.

\section{Acknowledgment}

This study was supported by a clinical research grant-in-aid from the Seoul Metropolitan Government-Seoul National University Boramae Medical Center (03-2011-10).

\section{Disclosure}

The authors report no conflicts of interest in this work.

\section{References}

1. Vestbo J, Hurd SS, Agusti AG, et al. Global strategy for the diagnosis, management, and prevention of chronic obstructive pulmonary disease: GOLD executive summary. Am J Respir Crit Care Med. 2013;187(4): 347-365.

2. Crowell MD, Zayat EN, Lacy BE, Schettler-Duncan A, Liu MC. The effects of an inhaled beta(2)-adrenergic agonist on lower esophageal function: a dose-response study. Chest. 2001;120(4):1184-1189.

3. Mokhlesi B, Morris AL, Huang CF, Curcio AJ, Barrett TA, Kamp DW. Increased prevalence of gastroesophageal reflux symptoms in patients with COPD. Chest. 2001;119(4):1043-1048.

4. Kempainen RR, Savik K, Whelan TP, Dunitz JM, Herrington CS, Billings JL. High prevalence of proximal and distal gastroesophageal reflux disease in advanced COPD. Chest. 2007;131(6):1666-1671.

5. Raghu G, Freudenberger TD, Yang S, et al. High prevalence of abnormal acid gastro-oesophageal reflux in idiopathic pulmonary fibrosis. Eur Respir J. 2006;27(1):136-142.

6. Koufman JA. The otolaryngologic manifestations of gastroesophageal reflux disease (GERD): a clinical investigation of 225 patients using ambulatory 24-hour $\mathrm{pH}$ monitoring and an experimental investigation of the role of acid and pepsin in the development of laryngeal injury. Laryngoscope. 1991;101(4 Pt 2 Suppl 53):1-78.

7. Koufman JA. Laryngopharyngeal reflux is different from classic gastroesophageal reflux disease. Ear Nose Throat J. 2002;81(9 Suppl 2): 7-9.

8. Belafsky PC, Postma GN, Koufman JA. Validity and reliability of the reflux symptom index (RSI). $J$ Voice. 2002;16(2):274-277.
9. Beaver ME, Stasney CR, Weitzel E, et al. Diagnosis of laryngopharyngeal reflux disease with digital imaging. Otolaryngol Head Neck Surg. 2003;128(1):103-108.

10. Belafsky PC, Postma GN, Koufman JA. The validity and reliability of the reflux finding score (RFS). Laryngoscope. 2001;111(8):1313-1317.

11. Postma GN, Belafsky PC, Aviv JE, Koufman JA. Laryngopharyngeal reflux testing. Ear Nose Throat J. 2002;81(9 Suppl 2):14-18.

12. Eryuksel E, Dogan M, Olgun S, Kocak I, Celikel T. Incidence and treatment results of laryngopharyngeal reflux in chronic obstructive pulmonary disease. Eur Arch Otorhinolaryngol. 2009;266(8):1267-1271.

13. Kilic M, Ozturk F, Kirmemis O, et al. Impact of laryngopharyngeal and gastroesophageal reflux on asthma control in children. Int J Pediatr Otorhinolaryngol. 2013;77(3):341-345.

14. Jung YH, Chang DY, Jang JH, et al. [Reflux symptom index (RSI) and reflux finding score (RFS) of persons taking health checkup and their relationship with gastrofiberscopic findings]. Korean J Otolaryngol. 2007; 50(5):431-437. Korean.

15. Pacheco-Galvan A, Hart SP, Morice AH. Relationship between gastrooesophageal reflux and airway diseases: the airway reflux paradigm. Arch Bronconeumol. 2011;47(4):195-203.

16. Kim J, Lee JH, Kim Y, et al. Association between chronic obstructive pulmonary disease and gastroesophageal reflux disease: a national cross-sectional cohort study. BMC Pulm Med. 2013;13:51.

17. Liang B, Wang M, Yi Q, Feng Y. Association of gastroesophageal reflux disease risk with exacerbations of chronic obstructive pulmonary disease. Dis Esophagus. 2013;26(6):557-560.

18. Martinez CH, Okajima Y, Murray S, et al. Impact of self-reported gastroesophageal reflux disease in subjects from COPDGene cohort. Respir Res. 2014;15:62.

19. Casanova C, Baudet JS, del Valle Velasco M, et al. Increased gastrooesophageal reflux disease in patients with severe COPD. Eur Respir J. 2004;23(6):841-845.

20. Hwang YI, Park YB, Oh YM, et al. Comparison of Korean COPD guideline and GOLD initiative report in term of acute exacerbation: a validation study for Korean COPD guideline. J Korean Med Sci. 2014;29(8):1108-1112.

21. Rascon-Aguilar IE, Pamer M, Wludyka P, et al. Role of gastroesophageal reflux symptoms in exacerbations of COPD. Chest. 2006;130(4): 1096-1101.

22. Sakae TM, Pizzichini MM, Teixeira PJ, et al. Exacerbations of COPD and symptoms of gastroesophageal reflux: a systematic review and meta-analysis. J Bras Pneumol. 2013;39(3):259-271.

23. Gadel AA, Mostafa M, Younis A, et al. Esophageal motility pattern and gastro-esophageal reflux in chronic obstructive pulmonary disease. Hepatogastroenterology. 2012;59(120):2498-2502.

24. Amaris M, Dua KS, Naini SR, et al. Characterization of the upper esophageal sphincter response during cough. Chest. 2012;142(5): $1229-1236$. 


\section{Supplementary material}

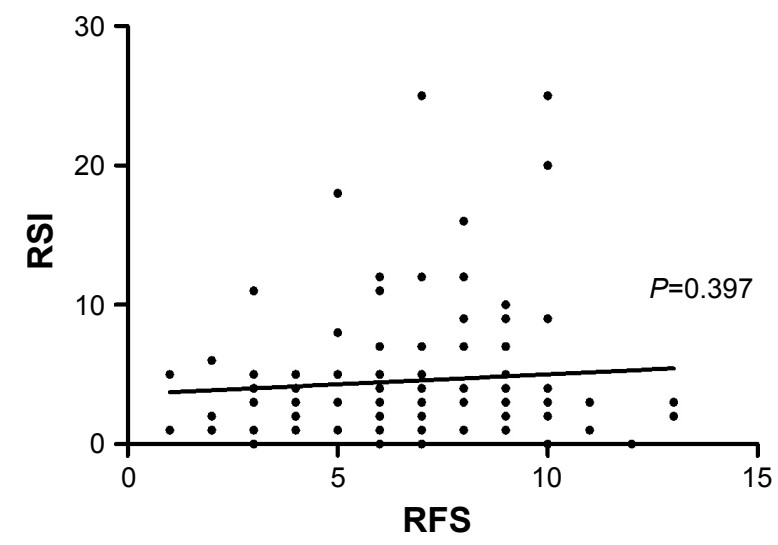

Figure SI Correlation between RFS and RSI in patients with COPD.

Abbreviations: COPD, chronic obstructive pulmonary disease; RFS, reflux finding score; RSI, reflux symptom index.

\section{Publish your work in this journal}

The International Journal of COPD is an international, peer-reviewed journal of therapeutics and pharmacology focusing on concise rapid reporting of clinical studies and reviews in COPD. Special focus is given to the pathophysiological processes underlying the disease, intervention programs, patient focused education, and self management protocols

\section{Dovepress}

This journal is indexed on PubMed Central, MedLine and CAS. The manuscript management system is completely online and includes a very quick and fair peer-review system, which is all easy to use. Visit http://www.dovepress.com/testimonials.php to read real quotes from published authors. 